\title{
Extending Holland's Hexagon: Procedures, Counseling Applications, and Research
}

\author{
Dale Prediger, Kyle Swaney, and Wei-Cheng Mau
}

\begin{abstract}
Since its introduction nearly 25 years ago, Holland's (1985) hexagon has remained in skeletal form. The hexagon is used to depict similarities and differences among occupations-but only six general types of occupations. The authors show in this article how to extend the basic concepts embodied in the hexagon. Procedures for locating counselees and occupations on the hexagon are illustrated. These procedures, which are compatible with scores from a wide variety of assessment instruments, can help counselees identify and explore occupational options. The authors also report research on the hexagon locations of 27 career groups.
\end{abstract}

An earlier, related article (Prediger, 1981) identified 10 career counseling instruments that provide scores relevant to Holland's (1985) hexagon (e.g., the Strong-Campbell Interest Inventory, the Kuder General Interest Survey, the Self-Directed Search). Because of the popularity of these instruments, it is likely that many readers have used hexagon-based concepts and scores. The purpose of this article is to describe both the need and a way to expand on the concepts embodied in the hexagon. To this end, the article builds on ideas first presented by Cole, Whitney, and Holland (1971); Miller (1985); and Prediger (1981). We begin with background information, already familiar to many readers, as a foundation for the subsequent discussion of career counseling applications and recent research.

\section{The Hexagon: 1969-1993}

First introduced nearly 25 years ago (Holland, Whitney, Cole, \& Richards, 1969), Holland's hexagon (Figure 1) depicts similarities and differences among Holland's (1985) six types of vocational personalities and work environments (e.g., occupations). Social (S) occupations, for example, are most similar (closest) to Artistic (A) and Enterprising (E) occupations. They are least similar to Realistic (R) occupations, which are on the other side of the hexagon. Their similarity to Conventional (C) and Investigative (I) occupations is intermediate. In general, the proximities of the six types of occupations indicate degree of similarity.

Although Holland's theory of careers has generated considerable research and writing (e.g., see Holland, 1985, for an overview), the hexagon has remained in skeletal form over the years. It shows similarities and differences among occupations-but only among six broad groups of occupations. Given the 12,099 unique occupations identified by the United States (U.S.) Department of Labor (1977), more than six groups are needed to portray similarities and differences. In fact, Holland (1985) has identified 71 groups of occupations on the basis of their three predominant Holland types ("3-letter codes"). Occupations in the ISA group, for example, are characterized by Investigative, Social, and Artistic work environments, in that order.

Holland (1985) advocated the use of 3-letter codes to identify occupations in line with a counselee's characteristics (e.g., interests). By completing an inventory that assesses Holland's types (e.g., the Self-Directed Search [SDS]) counselees obtain their three highest scores (3-letter code). They then use a look-up-list (e.g., the "Occupations Finder") to find occupational groups with their three letters, regardless of order (Holland, 1985). Thus, a counselee with an RIS code is told that the following are "suitable groups of occupations for you to consider" (Holland, 1985, p. 198): RIS, RSI, SIR, SRI, ISR, and IRS.

There seem to be at least four practical problems with the look-up-list approach to career exploration. 
1. Occupations in 3-letter code groups are quite diverse-for example, welders, cooks, filling station attendants, foresters, and opticians are all in the RIS group (Holland, 1985, p. 183). Counselees and counselors may not recognize how such occupations are related.

2. Because occupations in the 3-letter code groups are so diverse, it is impossible to give the groups descriptive titles. Thus, counselees must think in terms of abstract titles (e.g., RIS, SIR, CIR, SEC) or specific occupations. Especially in the early stages of career exploration, consideration of occupational fields would be more appropriate.

3. With abstract titles such as RIS, SIR, and CIR, similarities and differences among 71 occupational groups are difficult for counselees to comprehend.

4. The look-up-list approach to career exploration requires that a counselee consider only those 3-letter code groups containing the same three letters as the counselee's code-regardless of letter order. A counselee with an RIS code, for example, is not asked to consider the 74 occupations with RIE, RIC, and RIA codes (Holland, 1985)-these codes do not have an S as the third letter. The counselee, however, is asked to consider SIR occupations, even if the counselee's $\mathrm{S}$ score is much lower than is his or her R score. Thus, low-similarity occupations are explored, but high-similarity occupations are ignored.

The seriousness of this fourth look-up-list problem can be illustrated through use of lachan's (1984) 3-letter code similarity score, which was recently recommended by Holland (1987). RIS and the "matching" SIR code have a similarity score of 13-about the 25th percentile for "diverse samples" (Holland, 1987, p. 19). RIS and each of the ignored RIE, RIC, and RIA codes have a very high similarity score of 27; 28 -represents maximum similarity (i.e., identical 3-letter codes).

FIGURE 1

Holland's Hexagon and Underlying Dimensions

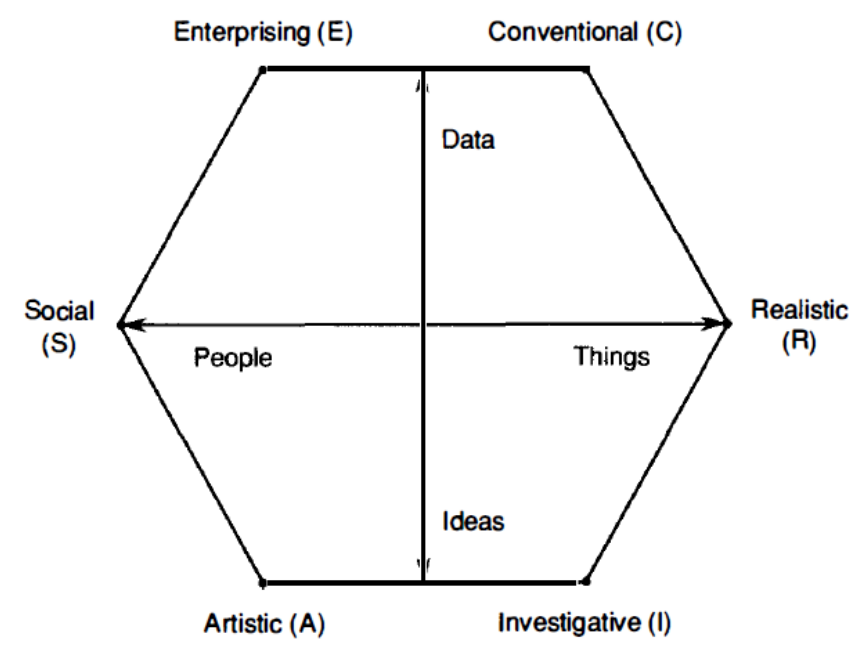

Note. From Lamb and Prediger, 1981, p. 2. Copyright 1981 by American College Testing. Adapted by permission.

Because of the aforementioned practical problems, use of a look-up-list can be a square-pegsquare-code exercise. It is important to note, however, that the look-up-list approach to career exploration makes no use of Holland's hexagon. If occupations and counselees could be located on the hexagon, itself, counselees would have an overview of the work world-and they could identify occupations in their "regions." They may wish to explore those occupations. Similar uses of a "visual occupational map" (Cole et al., 1971, p. 8) were suggested 20 years ago by Holland and his colleagues. Perhaps it is finally time to extend (map) the hexagon. 


\section{How To Extend The Hexagon}

A hexagon has two (and only two) dimensions. Recent research (Prediger, 1982; Rounds, in press) suggests that the following two work task dimensions underlie the hexagon: (a) working with data (e.g., facts, records) versus ideas (e.g., theories, insights) and (b) working with things (e.g., materials, machines) versus people (e.g., care, services). Figure 1 shows the locations of Holland's types on these two dimensions. If a data-ideas (D/I) score and a things-people (T/P) score were available for an occupation (or a counselee), the occupation (or the counselee) could be located on the two dimensions-that is, on the hexagon.

Prediger (1981) provided formulas for obtaining D/I and T/P scores from 3-letter codes. To use the formulas, the letters in the code must first be transformed to scores. The best assignment of scores to 3-letter codes is a matter for further research; however, the assignment of scores of 4, 2, and 1 to the Holland types that rank first, second, and third has received empirical support (Prediger, 1981, 1982). Holland types not in the 3-letter codes are assigned scores of 0 .

Once the 4-2-1 scores have replaced 3-letter codes, the scores are substituted for Holland's types in the following formulas:

$\mathrm{D} / \mathrm{I}$ score $=0.00(\mathrm{R})-1.73(1)-1.73(\mathrm{~A})+0.00(\mathrm{~S})+1.73(\mathrm{E})+1.73(\mathrm{C})$

$\mathrm{T} / \mathrm{P}$ score $=2.00(\mathrm{R})+1.00(1)-1.00(\mathrm{~A})-2.00(\mathrm{~S})-1.00(\mathrm{E})+1.00(\mathrm{C})$

The weights applied to Holland's types are based on the geometry of the hexagon, as described by Prediger and Vansickle (1992). The D/I scores can range from -10 to +10 (rounded), and the T/P scores can range from -11 to +11 . The zero point on each scale represents the origin (middle) of Figure 1.

After the $\mathrm{D} / \mathrm{I}$ and T/P scores are obtained, they are used to locate the 3-letter code on the hexagon. Suppose one wished to find the hexagon location of an occupation with a CIR code (e.g., adding machine operator; Holland, 1985). First, transform the letters in the code to 4-2-1 scores, as follows: $R=$ $1, I=2, A=0, S=0, E=0$, and $C=4$. Then replace Holland's types in the $D / I$ and $T / P$ formulas with their corresponding scores. The resulting $\mathrm{D} / \mathrm{I}$ and $\mathrm{T} / \mathrm{P}$ scores are 3.46 and 8.00 . Thus, $\mathrm{CIR}$ occupations would be located near the things pole on the data (upper) side of the T/P axis (see Figure 1).

Fortunately, for the mathematically disinclined, Miller (1985) described a simple, graphic procedure for approximating the hexagon locations obtained from the D/I and T/P formulas. Possibly because Miller's procedure was presented in the context of the World-of-Work Map (discussed later) rather than Holland's hexagon, its significance has gone largely unnoticed. For this reason, the procedure is now described.

Suppose a counselee has a 3-letter code of ISA. To map the code, mark the first, second, and third letters on the hexagon (see Figure 2). Then, start at the center of the hexagon-a position that is neutral with respect to Holland's six types. Because the counselee's first letter (highest score) is I, draw a line to I. Then draw a line from I toward S, the second letter in the 3-letter code. This second line segment should be half as long as the first to approximate the lesser importance of the second letter. (Recall the 4-2-1 scores.) Finally, continue the line toward A. This third line segment should be half as long as the second to approximate the lesser importance of the third letter in the 3-letter code. As shown by Figure 2, the broken line representing the ISA code ends in Region 10. Hence, the counselee would be located in a hexagon region where ideas work tasks (relevant to Types I and A) and, to a lesser extent, people work tasks (relevant to Type $\mathrm{S}$ ) predominate.

Miller's procedure for mapping a 3-letter code and the aforemen-tioned formulas almost always result in the same hexagon region. When there is disagreement, the two procedures identify adjacent regions. The advantage of Miller's mapping procedure is that counselees can literally see how their hexagon locations are influenced by their scores. A table that translates any 3-letter code into one of the Figure 2 regions is also available (Prediger, 1981). The table is handy when hexagon regions are needed for a large number of occupations or counselees. 


\section{Career Counseling Applications}

The World-of-Work Map (American College Testing, 1988), shown by Figure 3, illustrates one way to extend ("flesh-out") the hexagon. The "bare-bones hexagon" forms the core of the map. Superimposed on it are the two work task dimensions cited earlier. Holland's six types and alternative titles appear on the periphery of the map. Arrows by the titles indicate that they blend together rather than exist as precise points $(R, I, A, S, E, C)$. For this reason, the map is rounded rather than hexagonal.

\section{FIGURE 2}

\section{Locating a Counselee's 3-Letter Code on the Hexagon}

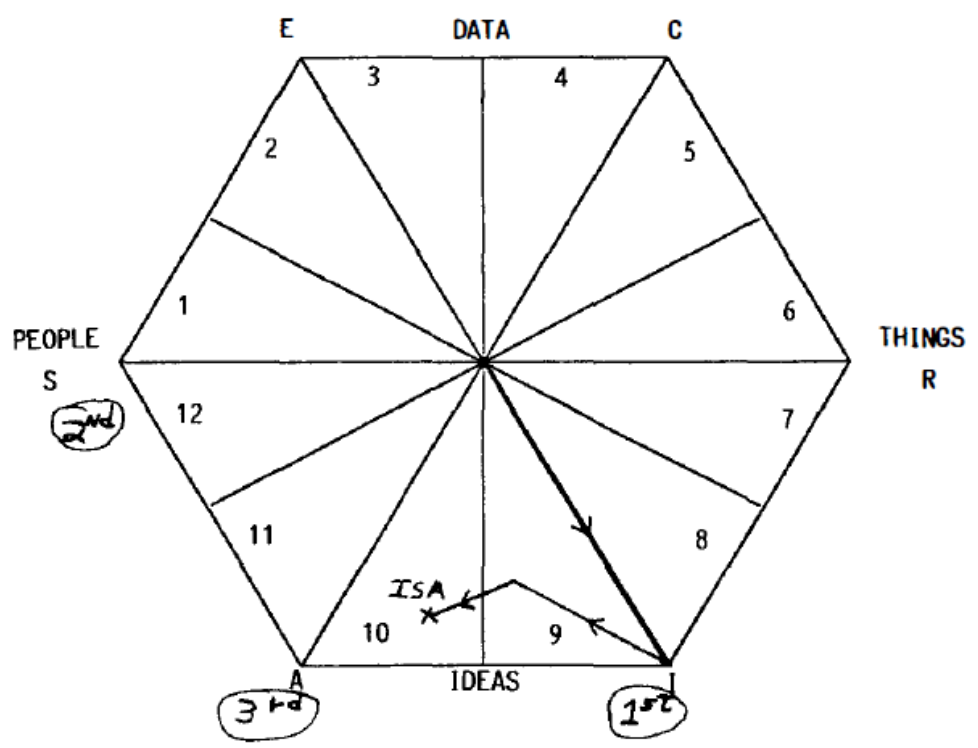

Note. Example Using an ISA code where I = Investigative, $\mathrm{S}=$ Social, $\mathrm{A}=$ Artistic.

The body of the World-of-Work Map shows the locations of 23 job families (groups of similar occupations) that encompass all occupations recognized by the U.S. Department of Labor (1977) in the Dictionary of Occupational Titles (DOT). Real-world data (e.g., interest scores for 991 career groups; job analysis data for the 12,099 DOT occupations) were used to group occupations into job families and to determine job family locations (ACT, 1988). Purpose of work and work setting were also considered.

As a result of the empirical and logical considerations noted earlier, World-of-Work Map job families are relatively homogeneous. Hence, they have names rather than 3 -letter codes for titles. The job family names and locations suggest similarities and differences in the work that is done and the people who do it. This overview of the work world is obscured when counselees use 3-letter codes-unless they have been trained to visualize similarities and differences among codes-for example, RIS, SIR, CIR, and SEC.

Counselors can find a counselee's location on the World-of-Work Map by (a) obtaining the counselee's 3-letter code from any instrument assessing Holland's types and (b) using the formulas, Miller's mapping procedure, or the table cited earlier. Counselees with an ESC code (hexagon Region 2), for example, might wish to look into job families in Regions 1, 2, and 3-for example, Marketing and Sales, Social and Government Services, Management and Planning. They can consider occupational fields (job families) rather than untitled code groups. Job Family Charts, which accompany the map, group 450 occupations by map region, job family, and prepara-tion level. The charts (available at no charge from the 
senior author) also key occupations to the Occupational Outlook Hand-book, high-school courses, and college majors.

Whether or not the World-of-Work Map is used, a counselee's hexagon location has many career counseling applications. A few are listed here:

1. Counselors can use the 3-letter codes for Holland's (1985) occupational groups to locate the groups on the hexagon. Counselees can then identify occupations close to their own hexagon locations. For example, counselees with an RIS code (hexagon Region 7) will see that occupations with RIE, RIC, and RIA codes are located nearby. As noted earlier, these 74 occupations are missed by the look-up-list approach to career exploration.

2. Counselors can use the 3-letter code for a counselee's preferred occupation to find the occupation's location on the hexagon. The counselee may wish to broaden career exploration by looking into occupations located nearby.

3. Counselors can determine whether a counselee's preferred occupation and measured interests have similar (congruent) hexagon locations. To the extent that the locations are similar, the preferred occupation is supported by measured interests.

4. Counselors can compare the hexagon locations of a counselee's interests and abilities. For example, locations based on the two SDS interest units and the three SDS ability units can be compared. Counselees with divergent interest-ability locations may have ambiguous SDS summary scores-the "bottom line" scores obtained by adding SDS interest scores to SDS ability scores.

Whatever the counseling application, counselors should point out that there is more to the work world than can be depicted by the hexagon, the World-of-Work Map, 3-letter codes, or look-up-lists.

\section{Research Applications}

The procedure for extending Holland's hexagon has many research applications. The primary purpose of the research reported here was to examine whether the hexagon locations of career groups, as determined by the vocational interests of group members, make good sense. To this end, the D/I and T/P formulas were applied to 3-letter codes for 27 career groups similar to World-of-Work Map job families. As described in the next section, the career groups consisted of 12 th graders and adults. A new measure of congruence between 3-letter codes-the Hexagon Congruence Index $(\mathrm{HCl})$-was used to analyze study results. Additional information regarding study procedures is provided by Mau, Swaney, and Prediger (1990).

\section{Method}

Instrument

The 1989 revision of the Unisex Edition of the ACT Interest Inventory (UNIACT; Swaney, 1990) was used to assess vocational interests. The revised UNIACT is a 90-item interest inventory with six 15-item scales corresponding to Holland's (1985) six types. Items cover work-relevant activities (e.g., write short stories, build a picture frame, conduct a meeting) using a three-choice response format consisting of dislike, indifferent, and like.

Coefficient alpha reliabilities for the sample of 1,548 12th-grade students described in the next section ranged from .85 to .92 for male students and from .86 to .92 for female students. Coefficient alpha reliabilities for a sample of 193 adults ranged from .77 to .90 for men and from .83 to .91 for women. UNIACT validity data include 3 -letter codes for more than 40,000 persons in 352 career groups. Specifics regarding UNIACT's psychometric characteristics have been provided by ACT (1988), Lamb and Prediger (1981), and Swaney (1990). 
FIGURE 3

The World-of-Work Map

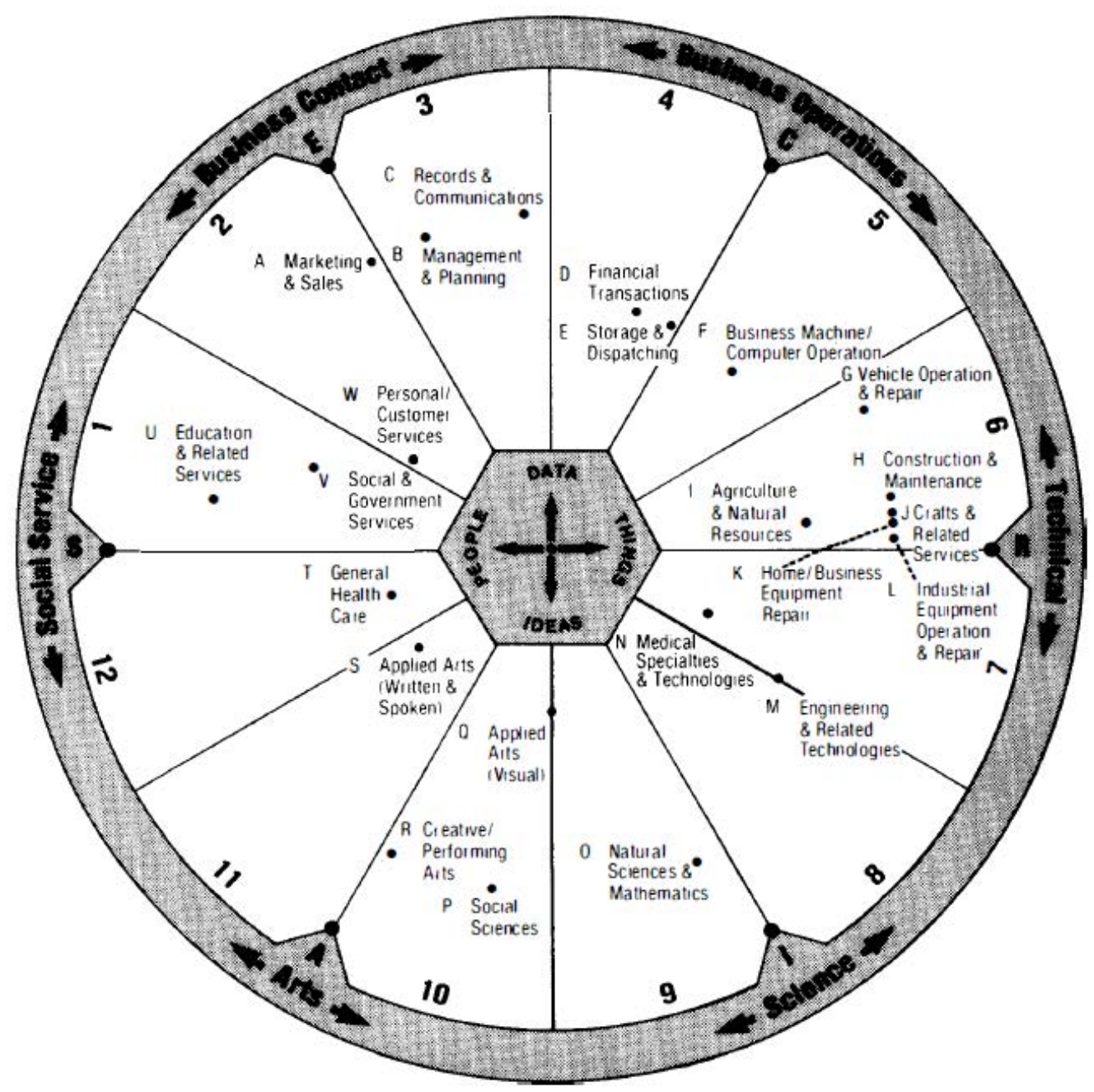

About the Map

- The World-of-Work Map arranges job families (groups of similar jobs) into 12 regions. Together, the job families cover all U.S. jobs. Although the jobs in a family differ in their locations, most are located near the point shown.

- A job family's location is based on its primary work tasks-working with DATA, IDEAS, PEOPLE, and THINGS.

- Six general areas of the work world and related Holland (1985) types are indicated around the edge of the map.

\section{Grade 12 Sample}

Guidance directors at 60 high schools nationwide were asked to participate in the equating of the previous form of UNIACT to the newly revised form. Schools were given the option to test all students in Grade 11, Grade 12, or both grades. Of the 15 schools that planned to test 12 th graders, 12 schools (2 from the west, 4 from the midwest, 4 from the south, and 2 from the east) actually completed testing. 
The initial Grade 12 sample consisted of 1,548 seniors ( 750 male students and 798 female students) with a complete set of UNIACT scores.

\section{Adult Sample}

Ten 2-year and 4-year colleges and universities nationwide were asked to participate in a try-out of items for the revised UNIACT. The 8 institutions that agreed to participate supplied ACT with computer tapes containing the names, addresses, birth dates, and academic majors for 44,092 undergraduates, age 25 or older, who were enrolled any time during the 1987-1988 school year.

For the purpose of sample selection, each adult's academic major was assigned to a Holland type or to a miscellaneous category that consisted of majors that could not be assigned (e.g., general studies). A mailing list was generated by randomly selecting 1,900 adults from each of six of the seven academic major categories. Because there were only 648 students in the R category, all were included in the mailing list. Adults in the sample received the interest items and a cover letter requesting their response to each item. Reminder postcards were sent to all Type $\mathrm{R}$ majors 1 week after the first mailing and to all nonrespondent men 3 weeks after the first mailing. (A low response rate was anticipated for these groups.)

Usable responses were received from 3,065 adults (1,061 men and 2,004 women). The response rate ( $25 \%$ of the mailing list sample) is similar to that obtained in the development of Strong-Campbell Interest Inventory Occupational Scales (Hansen \& Campbell, 1985).

Analyses indicated that the sample responding to the mailing was representative of the mailing list sample with regard to sex, age, college attended, and academic major. For example, both samples consisted of about $65 \%$ female respondents. The median age of the mailing list sample and the respondent sample did not differ appreciably (32 versus 33 years). Respondents ranged in age from 25 to 77 years of age.

\section{Formation of Career Groups}

When the 12th graders completed UNIACT, they responded to the following open-ended question: "You may have some career choices in mind for the future. Which career are you thinking about most?" Each student's career choice was assigned to a World-of-Work Map job family (unless it was unclassifiable). Students were asked to indicate career choice certainty by responding to the following question: "How sure are you that the career choice you selected will still be your first choice 1 year from now?" Students indicating that they were very certain or fairly certain were retained for the study. After all screens were applied, the final sample consisted of 1,078 twelfth graders.

Career choice (e.g., occupational preference, vocational aspiration) has had a long history as a validation criterion in interest research. In response to a question regarding their use of vocational aspiration as a validation criterion, Holland, Gottfredson, and Baker (1990) cited data showing that "aspirants for particular occupations resemble the employed adults in the same occupations" (p. 341 ).

Adults were also asked to report their career choice and level of certainty. In addition, they were asked to report their occupation. Occupations and career choices were assigned to job families. Persons who were employed less than half time, were unemployed, or who reported an unclassifiable occupation were excluded from the study.

An indication of job satisfaction was obtained by requiring each adult to meet two screens. First, current occupation had to agree with career choice. That is, they had to have the same Holland type. Second, respondents had to report they were very certain or fairly certain that their career choice would still be the same 1 year later. After all screens were applied, the final sample consisted of 725 adults.

The term career group is used, hereafter, to refer to the job family allocation for career choice (12th graders) or current occupation (adults). A total of 27 career groups-18 for 12 th graders and 9 for adults-had at least 20 cases. Smaller career groups were not mapped on the hexagon. 
Three-letter codes based on nationally normed UNIACT T scores were used to obtain D/I and T/P scores for each member of a given career group. Then, mean $D / I$ and T/P scores were obtained for all members of the career group. These mean scores were used to locate the career group on the hexagon.

\section{Results}

Study results illustrate the use of 3-letter codes to locate career groups on Holland's hexagon. The reasonableness of career group locations can be determined by comparing the locations with (a) the locations of Holland's types, (b) the locations of the D/I and T/P dimensions, and (c) the locations of other career groups. Some examples are provided in the next section.

\section{Locations of Grade 12 Career Groups}

As shown by the dots in Figure 4, the hexagon locations of students in the 18 career groups generally make good sense. For example, Group B (Management \& Planning) and Group D (Financial Transactions) are found "up North," near the data pole of the D/I dimension and between Holland's E and $C$ types. This seems reasonable given the considerable involvement with data work tasks of occupations such as business management and accounting. Group G (Vehicle Operation \& Repair) is found toward the things pole of the T/P dimension (Holland's R type); whereas Group U (Education \& Related Services) is found on the other side of the hexagon, toward the people pole (Holland's $S$ type).

The location of Group S (Applied Arts-Written and Spoken)-consisting mostly of 12th graders stating a preference for occupations such as lawyer, broadcaster, or journalist-is somewhat puzzling. One would expect a location that indicates more interest in ideas-related work tasks. Perhaps these 12th graders will experience dissatisfaction as they pursue their occupational preferences.

\section{Locations of Adult Career Groups}

Once again, the hexagon locations of the career groups generally make good sense. For this sample, Group S consisted mostly of persons in paralegal and legal assistant occupations. Hence, its location near the center of the data-ideas dimension is not as puzzling as the Group S location for 12th graders.

The interest scores for persons in Group T (primarily nursing occupations) place the group further toward the Ideas pole than might be expected. These results, however, are consistent with the results ob-tained by Lamb and Prediger (1981), who found that nursing students in six of seven samples scored highest on the UNIACT Science scale.

\section{Comparisons Using the Hexagon Congruence Index}

In the applications of hexagon mapping just described, similarity (congruence) of two hexagon locations was judged visually. A numerical index of congruence-the $\mathrm{HCl}$-is provided by the difference between the angles corresponding to two locations on the hexagon. (Mau et al. [1990] described a simple procedure for obtaining hexagon angles.) Thus, a counselee located at $100^{\circ}$ on the hexagon (in Region 3 on Figure 2) and an occupation located at $80^{\circ}$ (in Region 4) would have an $\mathrm{HCl}$ of $20^{\circ}$. This value can be compared with benchmark values such as an $\mathrm{HCl}$ of $60^{\circ}$ for adjacent Holland types and an $\mathrm{HCl}$ of $180^{\circ}$ for opposite types. $\mathrm{HCl}$ values range from $0^{\circ}$ (maximum congruence) to $180^{\circ}$ (minimum congruence).

The World-of-Work Map provides an external basis for examining the reasonableness of career group locations on the hexagon. That is, one can compare the career group (i.e., job family) locations obtained in this study (Figure 4) with job family locations on the World-of-Work Map (Figure 3).

Even though the World-of-Work Map shows the locations of job families on the two work tasks dimensions, the map locations and the locations obtained in this study are not strictly comparable. For example, many occupations included in the World-of-Work Map job families are not represented in this 
study's career groups. Also, the information used to determine World-of-Work Map job family locations included job analysis data in addition to interest scores (as noted earlier).

FIGURE 4

Locations of Career Groups on Holland's Hexagon

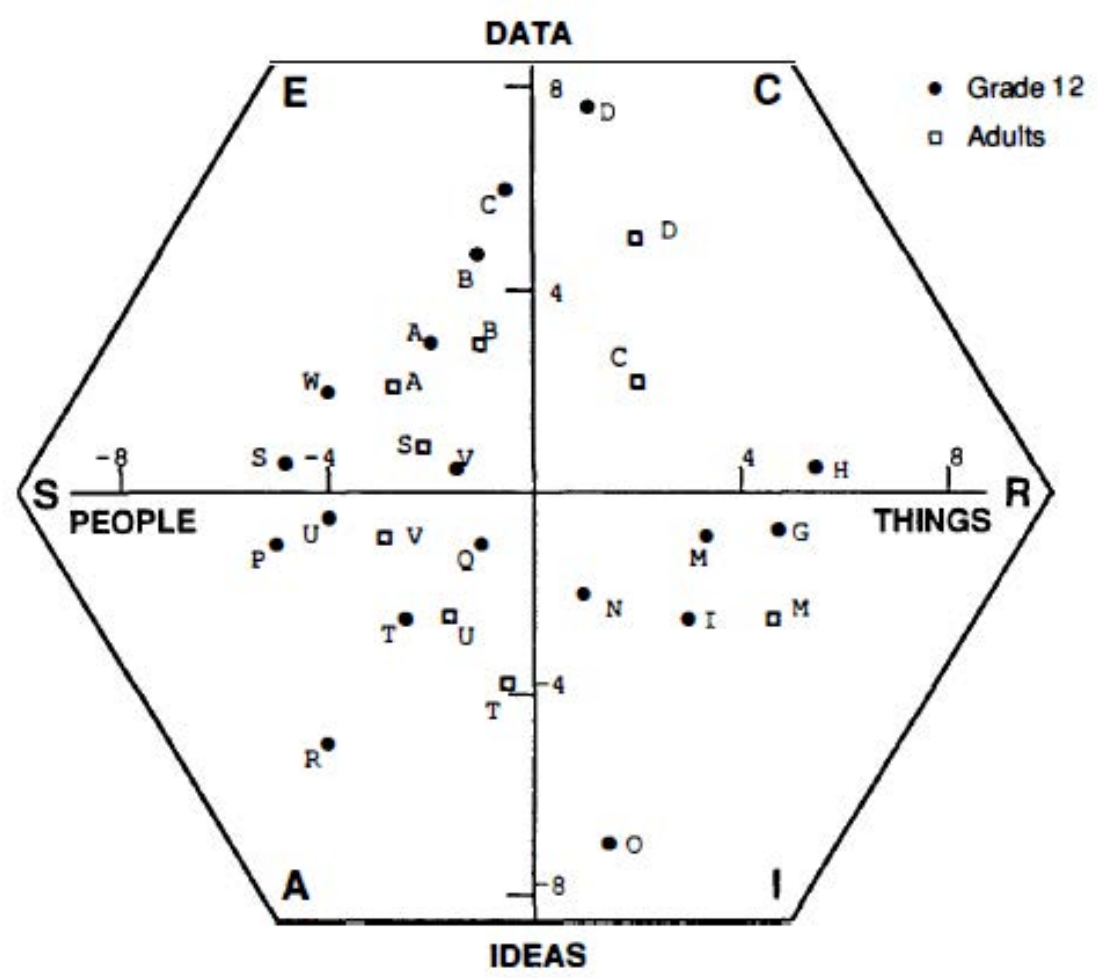
A: Marketing \& Sales
B: Management \& Planning
C: Records \& Communications
D: Financial Transactions
G: Vehicle Operation \& Repair
$\mathrm{H}$ : Construction \& Maintenance
I: Agriculture \& Natural Resources
M: Engineering \& Applied Technologies
$\mathrm{N}$ : Medical Specialties \& Technologies
O: Natural Sciences \& Mathematics P: Social Sciences
Q: Applied Arts (Visual)
R: Creative/Performing Arts
S: Applied Arts (Written \& Spoken) T: General Health Care
U: Education \& Related Services
V: Social \& Government Services
W: Personal/Customer Services

Nevertheless, an inspection of Figures 3 and 4 shows that the hexagon locations of career groups and job families are generally similar. (Compare, for example, Career Groups A, B, and C with Job Families A, B, and C.) The $\mathrm{HCl}$ scores for career group and job family pairs bear this out. For the Grade 12 career groups, the $\mathrm{HCl}$ scores range from $0^{\circ}$ to $69^{\circ}$, with a mean of $22^{\circ}$. For the adult career groups, the $\mathrm{HCl}$ scores 
range from $1^{\circ}$ to $71^{\circ}$, with a mean of $34^{\circ}$. As noted earlier, the $\mathrm{HCl}$ for adjacent Holland types is $60^{\circ}$-more than twice the average $\mathrm{HCl}$ across all 27 career groups $\left(26^{\circ}\right)$.

Figure 4 can also be used to compare the locations of Grade 12 and adult career groups. Despite the different procedures used in forming the groups, and the somewhat different sets of occupations making up the career groups, the locations of corresponding career groups for these two samples show a surprising level of similarity. (Compare, for example, Groups A, B, and C across the two samples.) $\mathrm{HCl}$ scores for the nine pairs of Grade 12 and adult career groups range from $3^{\circ}$ to $59^{\circ}$, with a mean of $25^{\circ}$. Additional observations are left to the reader.

\section{Discussion}

Study results illustrate the use of 3-letter codes to locate career groups on Holland's hexagon. Because numerous groups can be located on the same hexagon, the location of one group can be easily compared with the locations of other groups. Comparisons can be made by visual inspection, by using a congruence index such as the $\mathrm{HCl}$, or both.

Other congruence indexes have been devised to assess agreement between pairs of 3-letter codes. As noted earlier, Holland (1987) recommended an index developed by lachan (1984). Surprisingly, this index and a popular alternative (Zener \& Schnuelle, 1976) do not take relationships among Holland's types into account. Instead, both indexes are based on letter matches (e.g., are R and C in both 3-letter codes?) and letter position matches (e.g., is R the first letter in both codes?). For these indexes, the standard RIASEC sequence of relationships could just as well be IERSAC. The $\mathrm{HCl}$ does take relationships among Holland's types into account. The $\mathrm{HCl}$ also reports congruence on a universal scale (degrees) that has intuitive meaning when anchored to the hexagon. The Zener-Schnuelle and lachan congruence measures use arbitrary, unanchored scales.

In their article proposing a visual occupational map, Holland and his colleagues (Cole et al., 1971) expressed concern "when occupations have divergent interest patterns" (p. 5), even though they found "few cases of this kind" (p. 5). The procedure for extending Holland's hexagon seems to address their concern. The procedure provides a synthesis of divergent interest patterns-a common way of addressing inconsistencies in counseling and research. The nature of this synthesis can be seen by applying Miller's mapping procedure to a 3-letter code such as $\mathrm{SCl}$. The code is located in hexagon Region 1, near the center of the hexagon. Each letter in the 3-letter code influences the code's location. Note also that the location is not an all-or-none label. Occupations with divergent interest patterns are not called Ss, Cs, and so forth, on the basis of what may be a 1- or 2-point difference in the scores underlying their 3-letter codes.

\section{Toward A Full-Bodied Hexagon}

It may be possible to improve on procedures for extending Holland's (1985) hexagon. Even now, it should be apparent that the hexagon can (a) provide an overview of a work world comprising thousands of occupations; (b) help counselees identify occupational options that are congruent with their personal characteristics; and (c) provide counselors and researchers with ways (visual and numerical) to communicate similarities and differences among occupations-not just six broad groups of occupations or abstract, 3-letter code lists. Fleshed out, the hexagon seems to be healthier than ever.

\section{References}

American College Testing. (1988). Interim psychometric handbook/or the 3rd edition ACT Career Planning Program (1988 update). lowa City, IA: Author.

Cole, N. S., Whitney, D.R., \& Holland, J. L. (1971). A spatial configuration of occupations. Journal of Vocational Behavior, 1, 1-9.

Hansen, J. C., \& Campbell, D. P. (1985). Manual for the SVIB-SCII (4th ed.). Palo Alto, CA: Consulting Psychologists Press. 
Holland, J. L. (1985). Making vocational choices (2nd ed.). Englewood Cliffs, NJ: Prentice-Hall.

Holland, J. L. (1987). 1987 manual supplement for the Self-Directed Search. Odessa, FL: Psychological Assessment Resources.

Holland, J. L., Gottfredson, G.D., \& Baker, H. G. (1990). Validity of vocational aspirations and interest inventories: Extended, replicated, and reinterpreted. Journal of Counseling Psychology, 37, 337342.

Holland, J. L., Whitney, D. R., Cole, N. S., \& Richards, J. M., Jr. (1969). An empirical occupational classification derived from a theory of personality and intended/or practice and research (ACT Research Report No. 29). lowa City. IA: American College Testing.

lachan, R. (1984). A measure of agreement for use with the Holland classification system. Journal of Vocational Behavior, 24, 133-141.

Lamb, R.R., \& Prediger, D. J. (1981). Technical report for the Unisex Edition of the ACT Interest Inventory (UNIACT). lowa City, IA: American College Testing.

Mau, W., Swaney, K., \& Prediger, D. (1990). Mapping career groups on basic interest dimensions (ACT Research Report No. 90-7). lowa City, IA: American College Testing.

Miller, M. J. (1985). Counseling Region 99 clients. Journal of Employment Counseling, 22, 70-77.

Prediger, D. J. (1981). Getting ideas out of the DOT and into vocational guidance. Vocational Guidance Quarterly, 29, 293-305.

Prediger, D. J. (1982). Dimensions underlying Holland's hexagon: Missing link between interests and occupations? Journal of Vocational Behavior, 21. 259-287.

Prediger, D. J., \& Vansickle, T. R. (1992). Locating occupations on Holland's hexagon: Beyond RIASEC. Journal of Vocational Behavior, 40, 111-128.

Rounds, J. B. (in press). Vocational interests: Evaluating structural hypotheses. In R. V. Dawis \& D. Lubinski (Eds.), Assessing individual differences in human behavior: New concepts, methods, and findings. Minneapolis: University of Minnesota Press.

Swaney, K. (1990). Redevelopment of the Unisex Edition of the ACT Interest Inventory (UN/ACT): 19871989. Unpublished manuscript, American College Testing, lowa City, IA. United States Department of Labor. (1977). Dictionary of occupational titles (4th ed.). Washington, DC: U.S. Government Printing Office.

Zener, T. B., \& Schnuelle, L. (1976). Effects of the Self-Directed Search on high school students. Journal of Counseling Psychology, 23, 353-359. 